\title{
Sphenopalatine arteriovenous fistula complicating transsphenoidal pituitary surgery: A rare cause of delayed epistaxis treatable by endovascular embolization
}

\author{
Johanna Eneling, Per M. Karlsson, Sandro Rossitti \\ Department of Neurosurgery, University Hospital, Linköping, Sweden \\ E-mail: *Johanna Eneling - Johanna.Eneling@regionostergotland.se; Per M. Karlsson - Per.M.Karlsson@regionostergotland.se; \\ Sandro Rossitti - Sandro.Rossitti@regionostergotland.se \\ *Corresponding author \\ Received: II January $16 \quad$ Accepted: 17 June $16 \quad$ Published: 21 December 16
}

\begin{abstract}
Background: Vascular injuries in transsphenoidal surgery for pituitary adenomas are uncommon but can result in serious disability or death.

Case Description: A 46-year-old man, who underwent resection of a pituitary adenoma with suprasellar extension via a transsphenoidal approach, presented with massive epistaxis five days postoperatively. Angiography revealed an arteriovenous fistula (AVF) between the right sphenopalatine artery and a deep vein draining to the right internal jugular vein, as well as contrast agent extravasation at the fistula point. The AVF was catheterized and successfully occluded with N-butyl-2-cyanoacrylate.

Conclusions: Transsphenoidal pituitary surgery can be complicated by massive epistaxis from a lesion of a small branch of the external carotid artery. Airway protection through intubation and investigation with conventional digital subtraction angiography is recommended. The treatment of choice is endovascular embolization because it can be done immediately at the angiography suite.
\end{abstract}

Key Words: Complication, epistaxis, pituitary adenoma, sphenopalatine artery, transsphenoidal surgery

\begin{tabular}{|l|}
\hline Access this article online \\
\hline Website: \\
www.surgicalneurologyint.com \\
\hline DOI: \\
10.4103/2152-7806.196369 \\
\hline Quick Response Code: \\
\hline
\end{tabular}

\section{INTRODUCTION}

Transsphenoidal pituitary surgery has a low complication rate. However when complications do occur they can be devastating and, in the case of vascular injury, potentially lethal. When postoperative epistaxis occurs, a much feared cause is a ruptured pseudoaneurysm of the internal carotid artery. Immediate angiographic investigation should be performed on all patients that develop postoperative epistaxis in the aftermath of transsphenoidal pituitary surgery. ${ }^{[10,11]}$

This article presents, to the best of the authors' knowledge, the first case of postoperative delayed massive epistaxis from an iatrogenic sphenopalatine arteriovenous fistula after transsphenoidal pituitary surgery.

\section{CASE REPORT}

A previously healthy 46-year-old man was referred to our clinic because of visual symptoms and a nonfunctional

This is an open access article distributed under the terms of the Creative Commons Attribution-NonCommercial-ShareAlike 3.0 License, which allows others to remix, tweak, and build upon the work non-commercially, as long as the author is credited and the new creations are licensed under the identical terms.

For reprints contact: reprints@medknow.com

How to cite this article: Eneling J, Karlsson PM, Rossitti S. Sphenopalatine arteriovenous fistula complicating transsphenoidal pituitary surgery: A rare cause of delayed epistaxis treatable by endovascular embolization. Surg Neurol Int 2016;7:SI053-6.

http://surgicalneurologyint.com/Sphenopalatine-arteriovenous-fistula-complicatingtranssphenoidal-pituitary-surgery:-A-rare-cause-of-delayed-epistaxis-treatable-byendovascular-embolization/ 
pituitary adenoma with suprasellar growth that compressed the optic chiasm [Figure 1]. The tumor was resected via a transnasal, transsphenoidal microsurgical approach through the right nasal cavity. The tumor was tightly attached to the sellar diaphragm and there was a large opening to the suprasellar cistern after tumor removal. Tumor removal was macroscopically radical. Water-tight closure of the sella was achieved in layers using autologous fat tissue, collagen dural substitute, polyethylene sellar implant, fibrin glue, and repositioning of the saved remnants of the opened sphenoidal sinus mucosa. The nasal septum was realigned, as were the medial nasal turbinates on both sides. No bleeding from the sphenopalatine artery was encountered during the procedure. The patient had a momentary leakage of blood-tinted fluid from the nose when he was first mobilized from the supine to erect position. Four days post-peratively, as the patient was about to be discharged from our clinic to his local hospital, he had a brief transient episode of moderate epistaxis and was made to stay an extra night at the hospital. Early the next morning, 5 days postoperatively, the patient developed massive, life-threatening epistaxis from the right nasal cavity, as well as hematemesis. The patient was intubated, and a nasopharyngeal tamponade was applied. Computed tomography (CT) angiography did not reveal any injury to the internal carotid artery on either side. Digital subtraction angiography (DSA) of the right common carotid artery revealed irregularities in the wall of the right sphenopalatine artery and an arteriovenous shunt to a vein directed toward the internal jugular vein, with contrast agent extravasation at the fistula point [Figure 2]. A microcatheter was navigated into the sphenopalatine artery [Figure 3], and embolization of the arteriovenous fistula was done using $0.5 \mathrm{ml}$ glue (N-butyl-2-cyanoacrylate and Lipiodol in proportion 1:2).

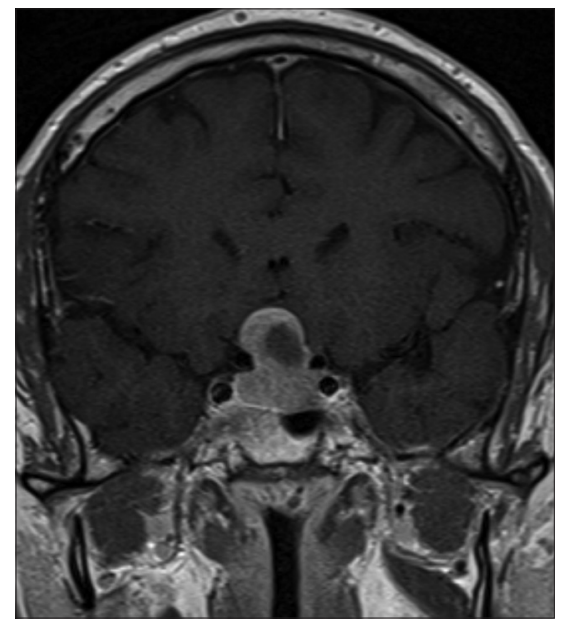

Figure I: Contrast-enhanced TI-weighted magnetic resonance imaging in coronal view showing a nonfunctioning pituitary adenoma. The tumor size was $2.5 \times 2 \times 2 \mathrm{~cm}$, with suprasellar extension and compression of the optic chiasm
The microcatheter was removed. Angiography of the right common carotid artery did not show any remaining arteriovenous shunt or contrast agent extravasation; the posterior septal branch of the sphenopalatine artery was occluded [Figure 4], indicating this branch as the lesion site. Angiography of the right internal carotid artery showed no sign of arterial injury or angiographic complications. Angiography of the left common, internal, and external carotid arteries revealed normal vessel anatomy. After embolization, all tamponades were removed and there was no active bleeding. The patient was stable overnight, he was successfully extubated the following day and he remained neurologically intact. On clinical follow-up, 2 months later, the patient was doing very well.

\section{DISCUSSION}

Transsphenoidal pituitary surgery is considered to be a safe procedure with reported mortality rates at approximately $1 \%$. Complications include anterior pituitary insufficiency, diabetes insipidus, cerebrospinal fluid fistulas and, less commonly, carotid artery injuries, hypothalamic injuries, loss of vision, and meningitis. ${ }^{[4]}$ Vascular injuries in transsphenoidal surgery for pituitary adenomas are particularly feared because they can result in serious disability, and even death. The most commonly reported vascular injuries are those concerning the internal carotid artery (reported to occur in $1.1 \%$ of all transsphenoidal operations), and include laceration, perforation, avulsion of dural branches, thrombosis, and other forms of injury that can cause massive hemorrhage, stroke, or lead to the formation of pseudoaneurysms and carotid-cavernous fistulas. ${ }^{[1,3,4]}$ Risk factors for iatrogenic internal carotid artery injury include large invasive adenomas, previous transsphenoidal surgery, previous radiation therapy, medical therapy (prolonged dopamine agonist treatment), and aggressive surgery of lesions invading the cavernous sinus. ${ }^{[4]}$

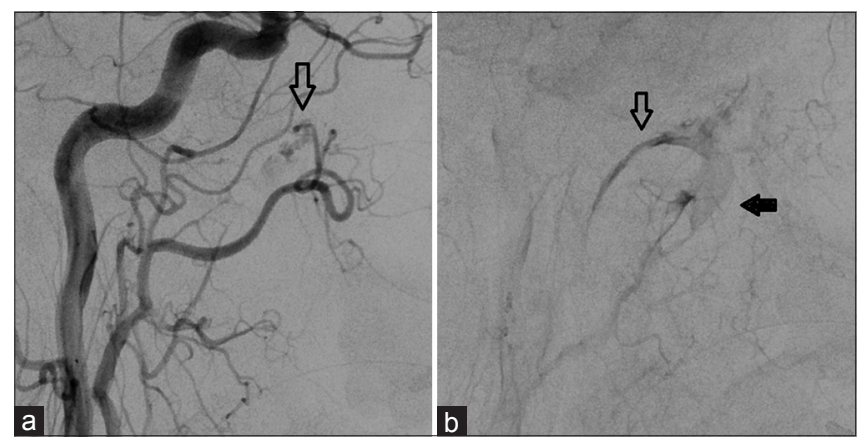

Figure 2: Digital subtraction angiography of the right common carotid artery in lateral view: (a) image in arterial phase showing a lesion in the sphenopalatine artery (arrow); (b) a later image showing arteriovenous shunt with venous filling (arrow) and extravasation of contrast agent (black arrow) 
Arteriovenous fistulas are direct connections between high-pressure arteries and low-pressure veins that bypass the capillary bed. A post-traumatic (or, as in the current case, iatrogenic) arteriovenous fistula can be caused by both penetrating and nonpenetrating trauma to an artery and an adjacent vein, and can develop immediately following injury or in a delayed fashion from a post-traumatic pseudoaneurysm. ${ }^{[7,15]}$ We interpret the arteriovenous fistula in our case to have developed in the latter fashion.

The sphenopalatine artery is the terminal branch of the internal maxillary artery and provides arterial supply to the nasal mucosa. It passes through the sphenopalatine foramen and divides into medial (septal) and lateral branches, the latter giving off branches to the superior, middle, and inferior nasal conchae. ${ }^{[18]}$ The septal branches pass to the posterior nasal septum and often require coagulation and division when surgical access is obtained between the middle turbinate and nasal septum for an anterior sphenoidotomy. Injury to the sphenopalatine artery can occur during enlargement of the sphenoidal opening because the artery is located in the hidden inferior lateral comer of the sphenoidal sinus. If it retracts toward the maxilla upon avulsion it can be difficult to coagulate. ${ }^{[6,11,17]}$ Despite its diminutive size in comparison to the internal carotid artery, sphenopalatine artery injuries can result in massive epistaxis. There are reports of sphenopalatine artery pseudoaneurysms having

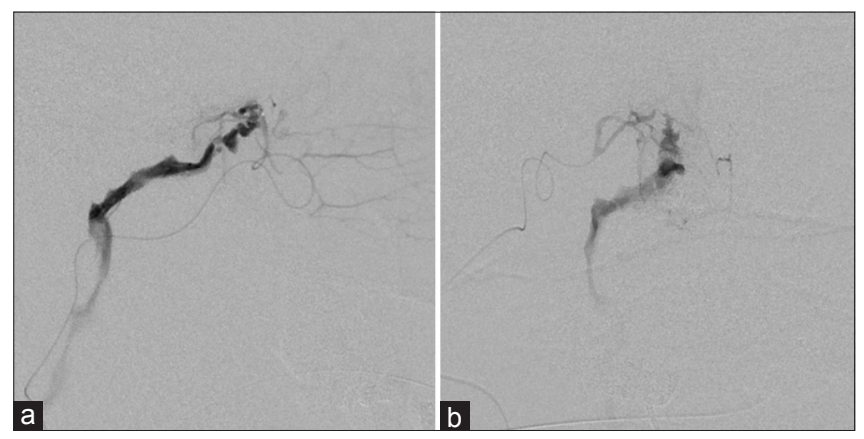

Figure 3: Digital subtraction angiography after microcatheterization of the right sphenopalatine artery showing the arteriovenous fistula before embolization: (a) Anterior posterior view; (b) lateral view occurred postoperatively after endoscopic sinus surgery and orthognatic surgery (notably Le Fort I osteotomy) as well as post-traumatically. ${ }^{[6,2,8,12,16]}$ Bleeding from the sphenopalatine artery, as from other branches of the external carotid artery, has been reported to have been successfully attenuated using detachable balloons, N-butyl-2-cyanoacrylate, particles, and platinum coils. $[9,13,14,19]$

Reports of sphenopalatine artery injuries in relation to transsphenoidal pituitary surgery are much less common than those of the internal carotid artery. We have found a total of 4 patients in two reports who developed angiographically diagnosed sphenopalatine artery pseudoaneurysms after transsphenoidal surgery for pituitary adenomas. ${ }^{[5,17]}$ The case characteristics are presented in Table 1.

The decision to let the patient undergo a CT angiography instead of taking him straight to the endovascular suite for DSA can, in retrospect, be viewed as questionable. It did cause a delay in definitive treatment and added an unnecessary contrast bolus. In a patient with life-threatening epistaxis, CT angiography should not be

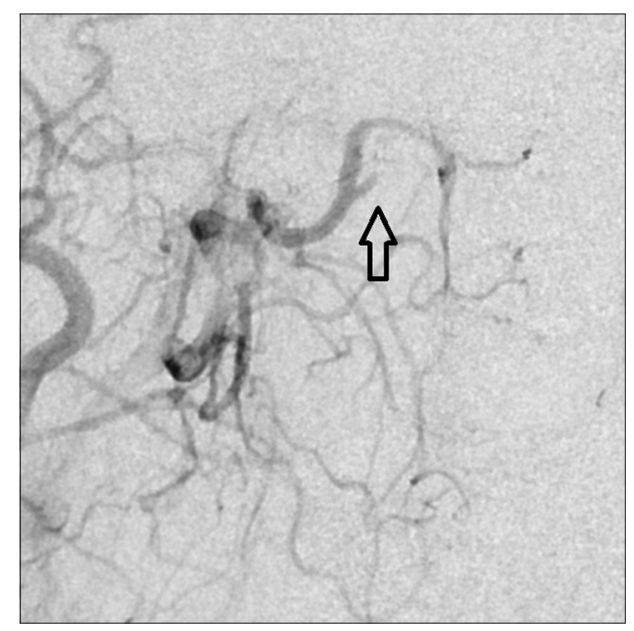

Figure 4: Digital subtraction angiography of the right common carotid artery in anterior posterior view:The arteriovenous fistula is occluded and the posterior septal branch of the sphenopalatine artery (arrow) is occluded

Table 1: Sphenopalatine artery injuries related to transsphenoidal pituitary surgery

\begin{tabular}{|c|c|c|c|c|c|}
\hline Reference & Sex/age & Clinical syndrome & $\begin{array}{c}\text { Previous transsphenoidal } \\
\text { surgery }\end{array}$ & $\begin{array}{l}\text { Presenting bleeding } \\
\text { episode }\end{array}$ & $\begin{array}{l}\text { Sphenopalatine artery } \\
\text { occlusion achieved by }\end{array}$ \\
\hline $\begin{array}{l}\text { Raymond } \\
\text { et al. }{ }^{[17]}\end{array}$ & $F / 34$ & Galactorhea & No & Postoperative day 11 & Fiber microcoils \\
\hline $\begin{array}{l}\text { Raymond } \\
\text { et al. }{ }^{[17]}\end{array}$ & $\mathrm{M} / 40$ & Acromegaly & No & Postoperative day 13 & Cyanoacrylate glue \\
\hline Cockroft et al. ${ }^{[5]}$ & $\mathrm{F} / 52$ & Prolactinoma & Yes & Postoperative day 15 & Polyvinyl alcohol particles \\
\hline Cockroft et al. ${ }^{[5]}$ & $\mathrm{F} / 40$ & ACTH-secreting adenoma & Yes & Postoperative day 17 & $\begin{array}{l}\text { Spontaneous occlusion at } \\
\text { angiography (vasospasm, } \\
\text { dissection, or thrombosis) }\end{array}$ \\
\hline
\end{tabular}


allowed to delay DSA and final treatment of the source of bleeding.

\section{CONCLUSION}

Massive postoperative epistaxis following transsphenoidal pituitary surgery requires swift treatment with immediate intubation to secure the airway, bleeding control through nasopharyngeal packing, and investigation with angiography. In this situation, a CT angiography is superfluous and a DSA is the investigation of choice. Although less common, massive epistaxis can result from lesions of a small branch of the external carotid artery such as the sphenopalatine artery. The treatment of choice, because it can be done almost without delay after diagnosis at the angiography suite, is endovascular embolization. There are many endovascular techniques available such as liquid embolics, particles, or coils that can be used. In the present case, embolization with N-butyl-2-cyanoacrylate was a successful method.

\section{Financial support and sponsorship Nil.}

\section{Conflicts of interest}

There are no conflicts of interest.

\section{REFERENCES}

I. Berker M, Aghayev K, Saatci I, Palaoğlu, Önerci M. Overview of vascular complications of pituitary surgery with special emphasis on unexpected abnormality. Pituitary 2010;13:160-7.

2. Campbell RG. Sphenopalatine artery pseudoaneurysm after endoscopic sinus surgery: A case report and literature review. Ear Nose Throat J 2012;91:E4-II.

3. Çinar C, Bozkaya H, Parildar M, Oran I. Endovascular management of vascular injury during transphenoidal surgery. Interv Neuroradiol 2013;19:102-9.

4. Ciric I, Ragin A, Baumgartner C, Pierce D. Complications of transsphenoidal surgery: Results of a national survey, review of the literature, and personal experience. Neurosurgery 1997;40:225-36.

5. Cockroft KM, Carew JF, Trost D, Fraser R. Delayed epistaxis resulting from external carotid artery injury requiring embolization: A rare complication of transsphenoidal surgery: Case report. Neurosurgery 2000;47:236-9.

6. Cohen S, Anastassov GE, Chuang SK. Posttraumatic pseudoaneurysm of the sphenopalatine artery presenting as persistent epistaxis: Diagnosis and management. J Trauma 1999;47:396-9.

7. Golshani K, Britz GW, Yoo A, West GA. Traumatic cerebral aneurysms secondary to penetrating intracranial injuries. In: Winn HR, editor. Youmans Neurological Surgery $6^{\text {th }}$ Ed. Philadelphia, PA: Saunders, Elsevier Inc.; 2011. p. $4000-1$.

8. Gökdoğan O, Kizil Y, Aydil U, Karamert R, Uslu S, lleri F. Sphenopalatine artery pseudoaneurysm: A rare cause of intractable epistaxis after endoscopic sinus surgery. J Craniofac Surg 2014;25:539-4I.

9. Halbach W, Hiqashida RT, Hieshima GB, Hardin CW. Arteriovenous fistula of the internal maxillary artery: Treatment with transarterial embolization. Radiology 1988; 168:443-5.

10. Jane JA Jr, Thapar K, Laws ER Jr. Pituitary tumors: Functioning and nonfunctioning. In: Winn HR, editor. Youmans Neurological Surgery. $6^{\text {th }}$ Ed. Philadelphia, Elsevier Saunders; 201I. p. I49I-2.

II. Jho DH, Jho DH, Jho HD. Endoscopic endonasal pituitary and skull base surgery. In: Quiñones-Hinojosa A, editor. Schmidek \& Sweet Operative Neurosurgical Techniques. $6^{\text {th }}$ Edition. Philadelphia, PA: Elsevier Saunders; 20I2. p. 260-I.

12. Kim YW, Baek MJ, Kim HD, Cho KS. Massive epistaxis due to pseudoaneurysm of the sphenopalatine artery: A rare post-operative complication of orthognathic surgery. J Laryngol Otol 2013;27:610-3.

13. Luo CB, Teng MM, Chang FC, Chang CY. Transarterial embolisation of acute external carotid blowout syndrome with profuse oronasal bleeding by N-butyl-cyanoacrylate. Am J Emerg Med 2006;24:702-8.

14. Martin-Granizo R, Caniego JL, de Pedro M, Dominguez L. Arteriovenous fistula after temporomandibular joint arthroscopy successfully treated with embolization. Int J Oral Maxillofac Surg 2004;33:30I-3.

15. Mitchell RN. Blood vessels. In: Kumar V, Abbas AK, Aster JC, editors. Robbins and Cotran Pathologic Basis of Disease, $9^{\text {th }}$ Ed. Philadelphia: Elsevier Saunders; 2015. p. 483-522.

16. Procopio O, Fusetti S, Liessi G, Ferronato G. False aneurysm of the sphenopalatine artery after Le Fort I osteotomy: Report of 2 cases. J Oral Maxillofac Surg 2003;61:520-4.

17. Raymond J, Hardy J, Czepko R, Roy D. Arterial injuries in transsphenoidal surgery for pituitary adenoma: The role of angiography and endovascular treatment. AJNR Am J Neuroradiol 1997; 18:655-65.

18. Salomon G, Faure J, Raybaud C, Grisoli F. The external carotid artery. Section I: Normal external carotid artery. In: Newton TH, Potts G, editors. Radiology of the skull and brain. Vol. 2. St. Louis: Mosby; 1974. p. 1246-74.

19. Takeuchi S, Takasato Y. latrogenic arteriovenous fistula of the superficial temporal artery after manual reduction of temporomandibular joint dislocation. J Craniofac Surg 201 I;22: 1959-6I. 